International Journal of Current Advanced Research

ISSN: O: 2319-6475, ISSN: P: 2319 - 6505, Impact Factor: SJIF: 5.995

Available Online at www.journalijcar.org

Volume 6; Issue 4; April 2017; Page No. 3260-3262

DOI: http://dx.doi.org/10.24327/ijcar.2017.3262.0240

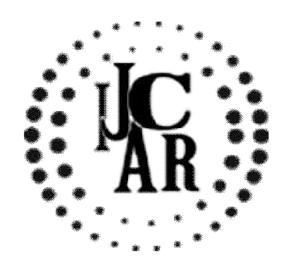

Review Article

\title{
KNOWLEDGE ABOUT LUNG CANCER AMONG MIDDLE AGED NON- MEDICAL FEMALES -A QUESTIONNAIRE BASED STUDY
}

\author{
Sandra Sagar and Brundha.M.P
}

Saveetha Dental College and Hospitals, Chennai-77

\begin{tabular}{|c|c|}
\hline A R T I C L E I N F O & A B S T R A C T \\
\hline Article History: & Aim: The aim is to carry a survey on lung cancer among middle aged non medical females. \\
\hline Received $19^{\text {th }}$ January, 2017 & $\begin{array}{l}\text { Objective: The objective of the research is to create awareness about symptoms, etiology } \\
\text { treatment and prevention of lung cancer. }\end{array}$ \\
\hline Received in revised form $20^{\text {th }}$ February, 2017 & Background: Lung cancer is gradually increasing in india with men being common and \\
\hline Accepted $22^{\text {nd }}$ March, 2017 & percentage of women increasing slowly. It is caused by smoking, air pollution, exposure \\
\hline Published online $28^{\mathrm{m}}$ April, 2017 & $\begin{array}{l}\text { to radon gases, rarely by genetics and passive smoking. Immediate chemotherapy or } \\
\text { radiotherapy treatment should be taken. }\end{array}$ \\
\hline Key words: & $\begin{array}{l}\text { Reason: With the exponential death due to lung cancer it is very important to educate } \\
\text { people on it. }\end{array}$ \\
\hline
\end{tabular}

Copyright $₫ 2017$ Sandra Sagar and Brundha.M.P. This is an open access article distributed under the Creative Commons Attribution License, which permits unrestricted use, distribution, and reproduction in any medium, provided the original work is properly cited.

\section{INTRODUCTION}

Lung cancer is the leading cause of deaths in developed countries and also rising at alarming rates in developing countries [1]. The worldwide incidence of lung cancer is $14 \%$ whereas it constitutes $6.8 \%$ of all cancers in India [2]. Both incidence and mortality from lung cancer in females is also increasing while it is declining in males in developed countries [3] Lung cancer is the leading cancer seen in both genders in India [2]. Tobacco smoking is an important risk factor for lung cancer among females in India [4] The present research is done with the aim to create awareness about symptoms, etiology, treatment and prevention of lung cancer among middle aged non medical females in South India.

\section{MATERIALS AND METHODS}

The questionnaire based study was carried out among healthy non-medical middle aged females of south India. The questionnaire comprised of 15 questions which were used to assess the awareness of lung cancer.

\section{RESULT}

About $65 \%$ people were aware about the word lung cancer.Among those $65 \%$ about $34 \%$ have got this awareness through media, $27 \%$ through their family members and $7 \%$ through their neighbours. Awareness about the causes of lung cancer, $81 \%$ of the study sample were aware about the causes of lung cancer.About $61 \%$ of the sample reported that smoking is the major cause of lung cancer.

*Corresponding author: Sandra Sagar

Saveetha Dental College and Hospitals, Chennai-77
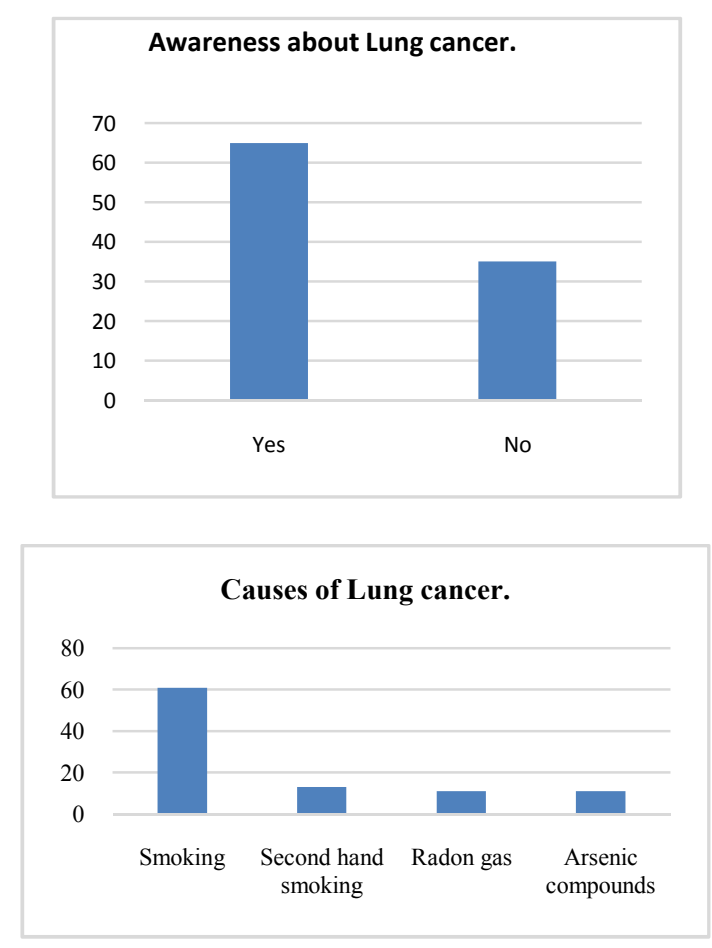

About the food substances that cause lung cancer, only $30 \%$ were aware that certain food items can also cause cancer. The most commonly mentioned food items were oils, colouring agents, tin packed foods, fast food and sea foods. 


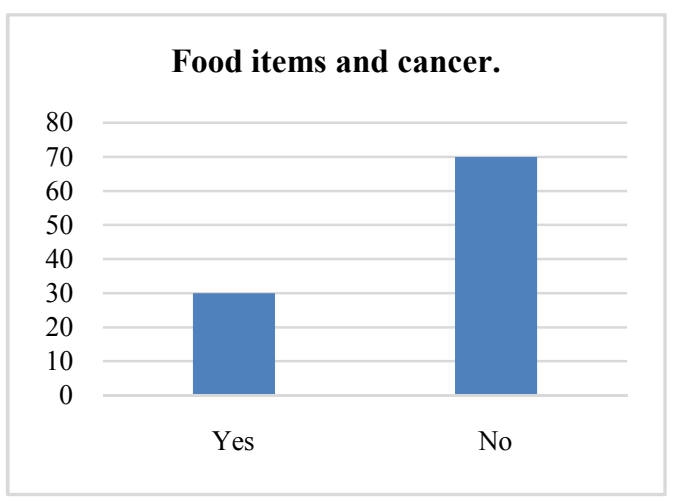

This study showed about $84 \%$ of the sample were aware that early detection can help in their treatment and $62 \%$ of the sample agreed that developing cancer is a matter of chance.

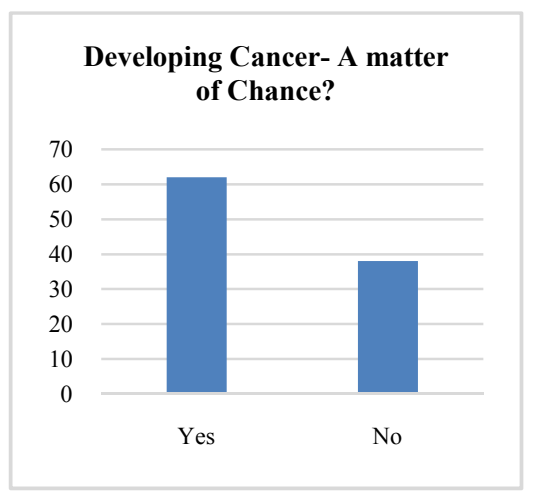

$57 \%$ of the study population showed that lung cancer is not caused by hereditary. This study showed that weight loss $(39 \%)$ is the most common early symptom of cancer, followed by wheezing (36\%).
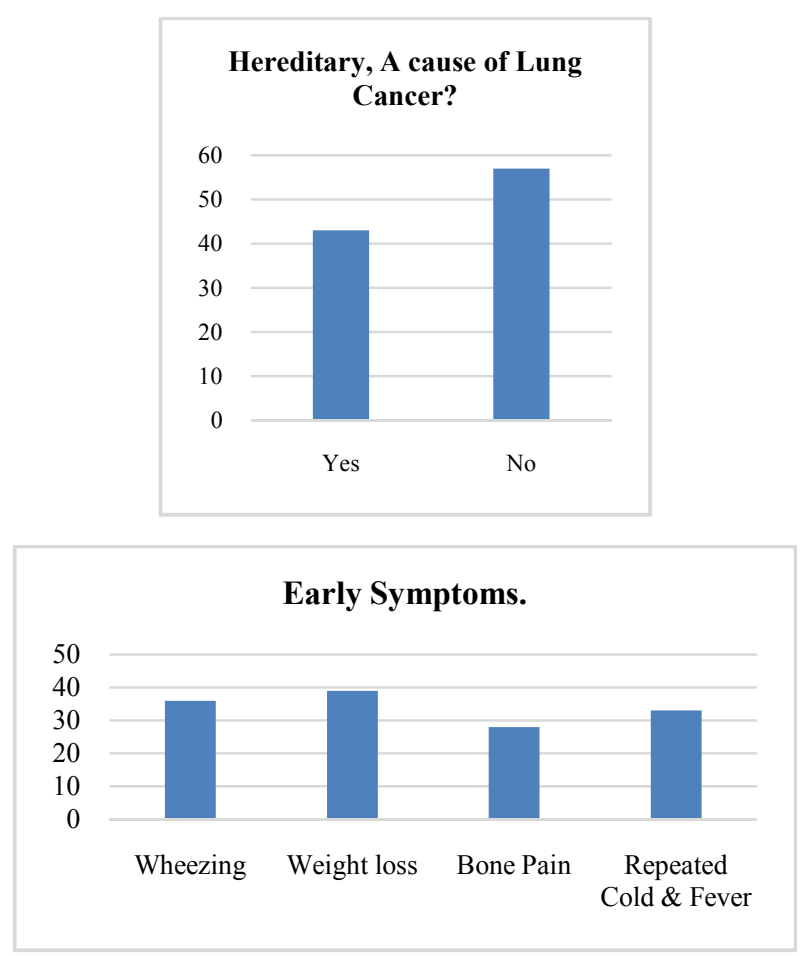

Fluid in chest was the most common late symptom $(42 \%)$ followed by shortness of breath (41\%) and coughing of blood $(39 \%)$.

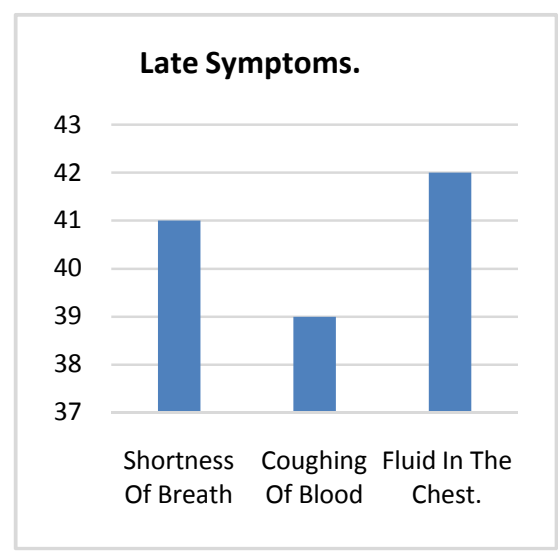

$64 \%$ of the sample were aware that TB and Lung cancer are closely related. The knowledge about the investigation methods showed Biopsy (47\%) and Blood test (47\%) are the most frequently used investigation methods. The common treatment found in this study is the combined therapy (36\%) of chemotherapy and radiotherapy.

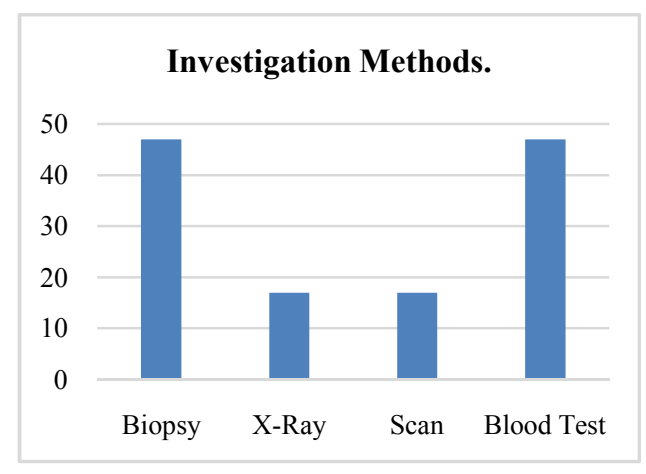

\section{TB and Lung Cancer}
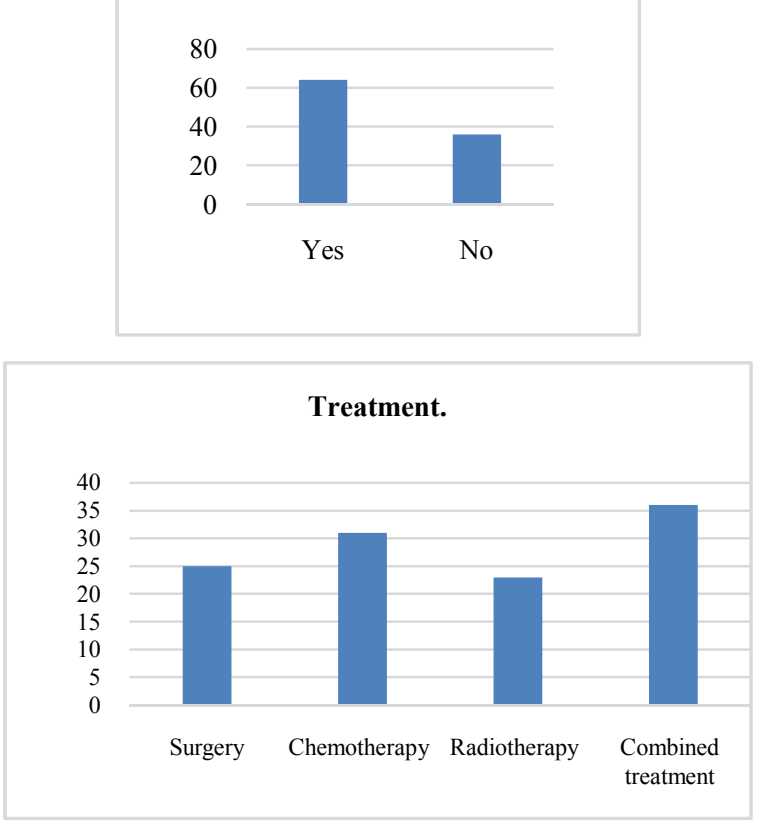

About the side effects of chemotherapy about $64 \%$ of the study sample showed hairloss is the major side effect followed by nausea (31\%) and vomiting (26\%). About 53\% people told that they are aware about the psychiatric distress faced by a cancer patient $72 \%$ of the study sample reported that to quit smoking is the most apt preventive measure which is followed by avoiding carcinogens (35\%) 

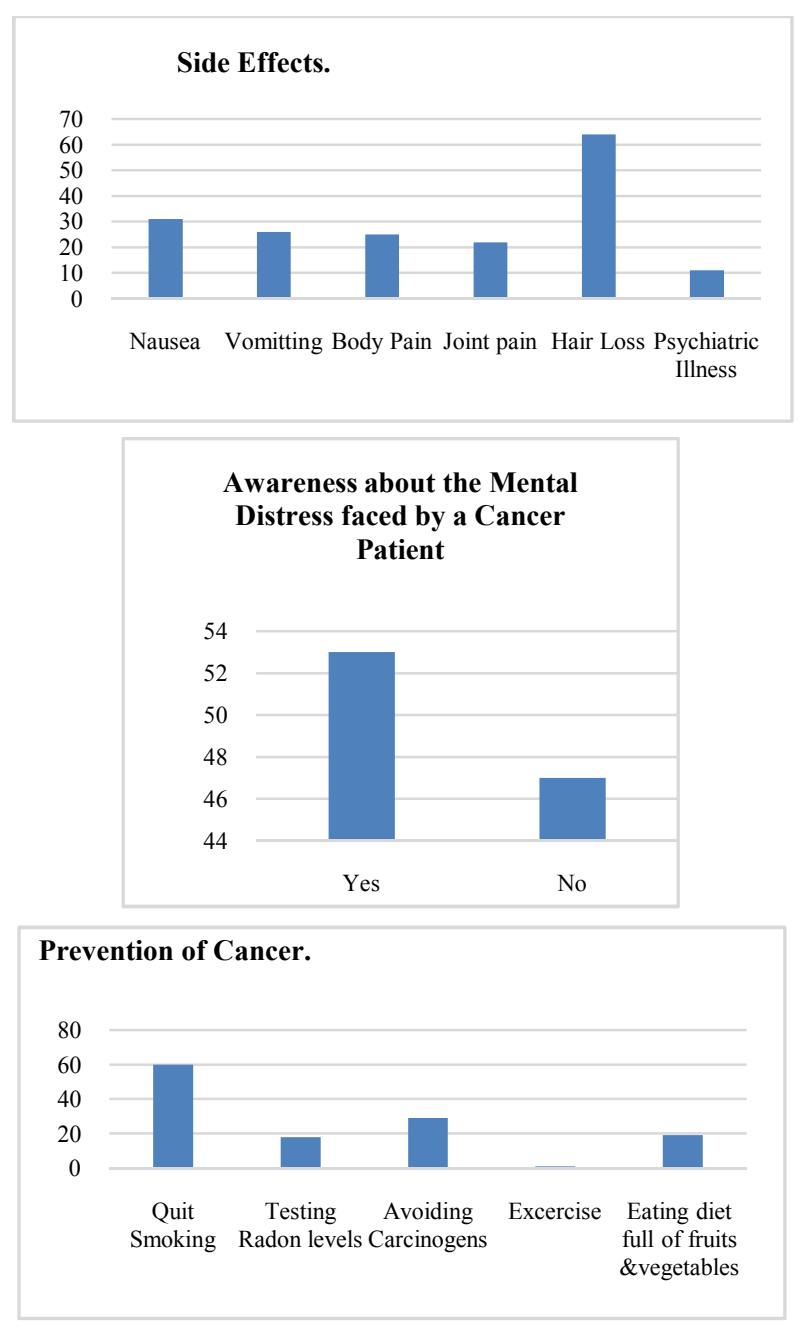

$72 \%$ of the study sample expressed that the males get affected the most because of smoking and the remaining $28 \%$ expressed that women are more affected more by lung cancer than males due to second hand smoking

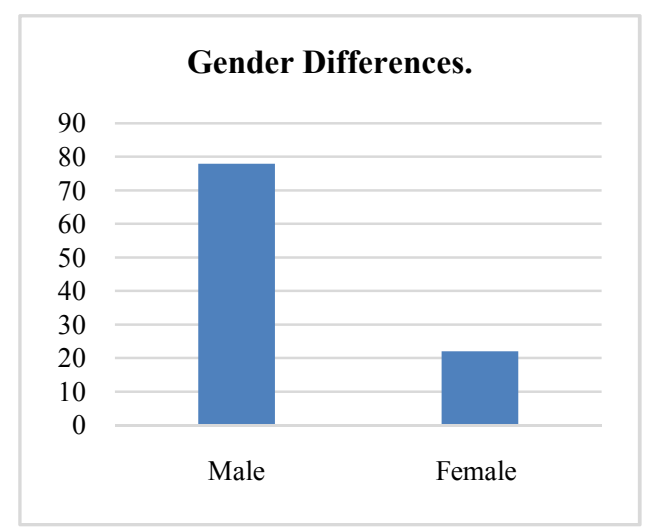

\section{DISCUSSION}

Lung cancer is the most common fatal malignancy among men and women in most countries of the world and the gender difference is narrowing [5]. In India, the incidence of lung cancer is increasing rapidly, mainly due to change in life style [6]. According to the population and hospital based National Cancer Registry (1986) of the Indian Council of Medical Research (ICMR), primary bronchogenic carcinoma constitutes $8 \%$ of all cancers in men and less than $1 \%$ of all cancers in women in India. When analysing the results in the above questionnaire about $54 \%$ of the study sample are very well aware about lung cancer, its causes, symptoms, investigations, treatment and preventive measures. According to a study, there will be $>170,000$ diagnosed cases of lung cancer. There will be $>160,000$ deaths from lung cancer. About $75-80 \%$ of lung cancers are associated with smoking. However, over $50 \%$ have stopped smoking. AND over 15-20\% NEVER smoked.[8] According to our present study about $72 \%$ showed that men who are more prone to smoking get affected by lung cancer and the women who get affected are also due to second hand smoking. About 36\% showed that the combined treatment is the best method of treatment for cancer. But there are many side effects of chemotherapy such as hairloss, nausea, vomiting, bone pain, joint pain. The persons with lung cancer also exhibhit severe breathing problems. The symptoms of lung cancer are closely related to tuberculosis. So it takes a long time for a person to get diagnosed with lung cancer as they get easily misinterepted with tuberculosis. The person initially gets breathing difficulties, repeated fever and cough which is the main reason it to be misinterpreted as tuberculosis. If lung cancer is detected early, it can be treated effectively without spreading to other parts. To quit smoking is the main preventive measure of lung cancer.

\section{CONCLUSION}

Lung Cancer is the major cause of deaths in India. According to the present study, it is seen that only about $54 \%$ of the non medical females are aware about lung cancer, its causes, symptoms, investigations, treaatment their preventive measures. So more awareness must be created through media. Awareness can also be created through hospital camps, some NGO programmes so that many people get aware of it and the victims of lung cancer start decreasing.

\section{References}

1. World Health Organization. Cancer in developed countries: assessing the trends. WHO Chron 1985; 39:109-11.

2. Nanda Kumar A. Consolidated report of the population based cancer registries, incidence and distribution of cancer, 1990-1996. National Cancer Registry Programme. New Delhi: Indian Council of Medical Resesarch; 2001.

3. Behera D, Balamugesh T. Lung cancer in India. Indian $J$ Chest Dis Allied Sci 2004; 46:269-81.

4. Behera D, Balamugesh T. Indoor air pollution as a risk factor for lung cancer in women. $J$ Assoc Physicians India 2005; 53:190-2.

5. Bal S. Screening for lung cancer. Hospital Today 2001; 6:609-11.

6. Majumdar SK Das, Nanda S, Goirola M. Brachytherapy in lung cancer. Hospital Today 2001; 6:609-11.

7. National Cancer Registry. Indian Council of Medical Research, Annual Report. New Delhi: Indian Council of Medical Research; 1986.

8. Lung Cancer Research-From Preventin to Cure.Dr.ravi Salgia. University of Chicago, 2006 